\title{
O LIXO COMO UMA PROBLEMÁTICA ANTROPOLÓGICA: ENTREVISTA COM FREEK COLOMBIJN
}

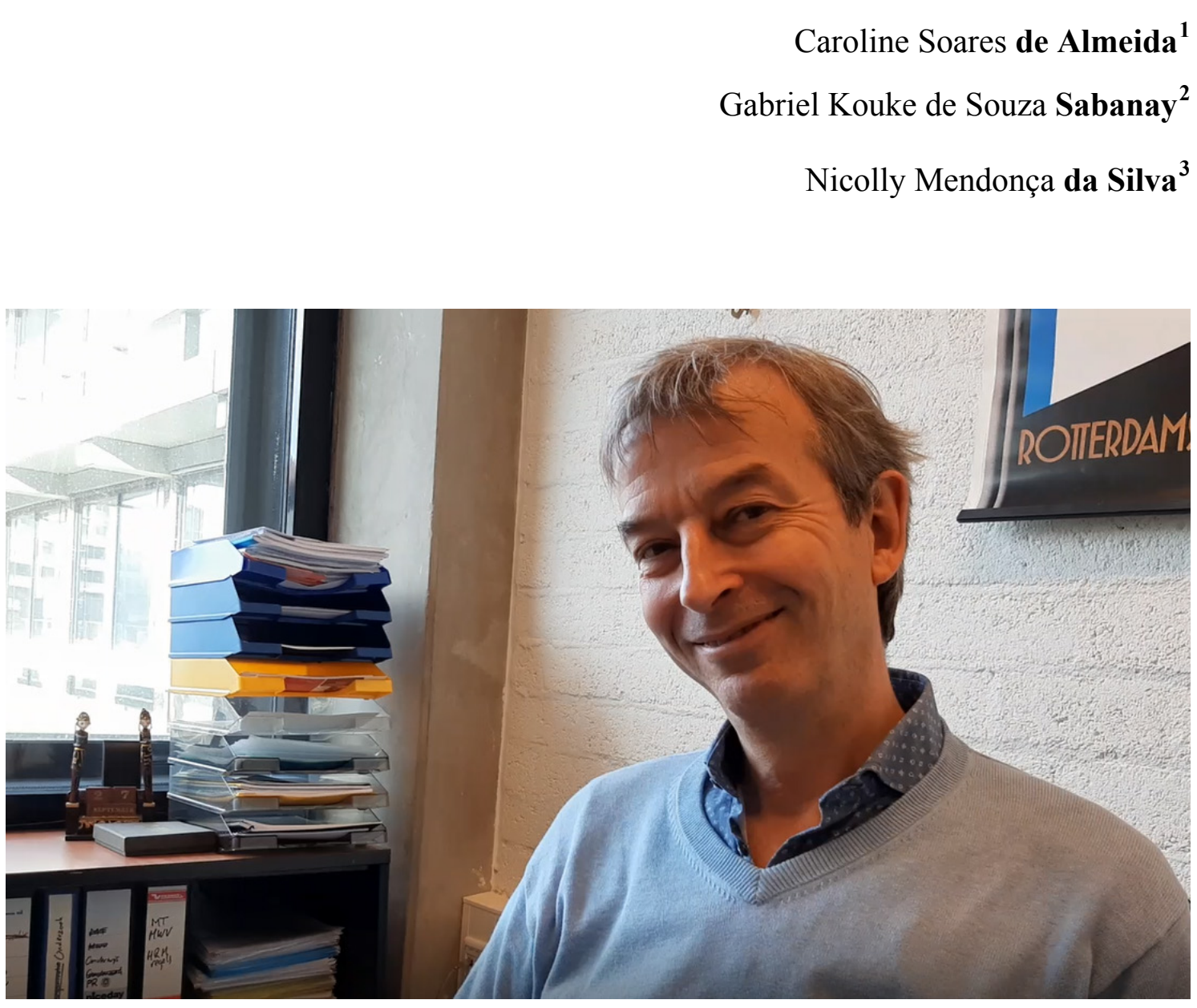

Dr. Freek Colombijn durante a entrevista em sua sala na VU Amsterdam (Foto: Caroline de Almeida)

A proposta de realizarmos uma entrevista ${ }^{4}$ com Freek Colombijn surgiu a partir da organização de um dossiê sobre os estudos produzidos por pesquisadores que participaram do convênio CAPES/NUFFIC ${ }^{5}$ pelo projeto "Economia circular:

\footnotetext{
${ }^{1}$ Universidade Federal de Santa Catarina, Brasil.Email: almeidacarol@yahoo.com. ORCID id: https://orcid.org/0000-0003-1361-6616.

${ }^{2}$ Universidade Federal de Santa Catarina, Brasil. Email: sabanay.gabriel@gmail.com. ORCID id: https://orcid.org/0000-0002-0729-0413

${ }^{3}$ Universidade Federal de Santa Catarina, Brasil.Email: nicollysilva2001@gmail.com. ORCID id: https://orcid.org/0000-0002-0079-1055

${ }^{4}$ A realização desta entrevista recebeu fomento do Programa CAPES/NUFFIC- bolsa na modalidade de pós-doutorado à pesquisadora Caroline Soares de Almeida - e de Iniciação Científica (IC/CNPq - UFSC) - aos graduandos Gabriel Kouke de Souza Sabanay e Nicolly Mendonça da Silva.

${ }^{5}$ Convênio existente entre as agências de fomento Coordenação de Aperfeiçoamento de Pessoal de Nível Superior (CAPES/Brasil) e Netherlands organisation for international cooperation in higher education (NUFFIC/Países Baixos).
} 
antropologias do lixo/resíduos sólidos e experiências inovadoras entre Holanda e Brasil”, ativo desde 2018. Há quase uma década Colombijn mantém diálogo direto com a Antropologia Brasileira em parcerias firmadas com a antropóloga Carmen Rial. Mais precisamente, desde 2011, através do primeiro projeto, submetido pelo mesmo convênio, intitulado "Modernidade, o meio ambiente e novas noções sobre o lixo e pureza" (2011 a 2015). Em 2016, o grupo lançou o livro "O poder do lixo: abordagens antropológicas dos resíduos sólidos". Juntos, são responsáveis pela orientação de mais de uma dezena de pesquisas que discutem diferentes temáticas dentro da área que abrange a Antropologia do Lixo/dos Resíduos Sólidos.

Intentava-se, com esse convênio, criar uma rede de pesquisadores que reunissem trabalhos sobre as múltiplas relações que pessoas possam manter com o que chamamos, de maneira provocativa, de lixo ${ }^{6}$ : classificações que dividissem lixo do que ainda tem serventia social; mecanismos de gestão de resíduos; poluição das águas; diferentes alternativas de consumo; preocupação coma emissão de carbonos; etc. A mudança no enfoque, de "noções sobre lixo" para "economias circulares", demonstrou uma mudança também nas problemáticas que ganharam maior relevância mais para o final da década de 2010. De maneira geral, essas problemáticas são encabeçadas pelas percepções de que os recursos naturais estão em colapso e de que o planeta não comporta mais a deposição dos resíduos no meio ambiente, além da emissão de gases que causam o efeito estufa. Poluição e esgotamento, essas são as principais características que definem o Antropoceno (Chua; Fair, 2019). A solução apontada por muitas organizações internacionais - e que dialoga com grande parte das pesquisas que fazem parte desse projeto - consiste no rompimento com o processo de produção linear e com o incentivo à implementação de economias circulares regionalizadas.

Tendo dupla formação, como antropólogo e historiador, Colombijn concluiu seu doutorado em Ciências Sociais pela Universidade de Leiden, em 1994. No decorrer de mais de três décadas, desenvolveu uma sólida carreira, sendo grande parte de suas pesquisas destinada a trabalhos de campo na Indonésia, em que conduziu seu interesse às problemáticas surtidas, sobretudo, no espaço urbano: violência, habitação, desenvolvimento urbano, história do espaço urbano, gestão do lixo, entre outras.

\footnotetext{
${ }^{6}$ A provocação em jogar com a ideia de lixo e resíduos é central no argumento que construiu o projeto.
} 
Esta entrevista foi gentilmente cedida em fevereiro de 2020, no Department of Social and Cultural Anthropology da Vrije Universiteit Amsterdam, onde Freek Colombijn atualmente é chefe. Foram abordadas questões relativas à formação acadêmica, principais influências teóricas, parcerias com Brasil e sobre o lugar da problemática dos resíduos sólidos nos seus trabalhos. Em sua fala, o antropólogo ainda nos mostra um pouco do seu olhar sobre a tradição antropológica holandesa, citando principais autores e linhas de pesquisa.

Caroline de Almeida - Poderia nos contar um pouco sobre sua carreira acadêmica?

Dr. Freek Colombijn - Sabe, meu histórico acadêmico, que é muito longo, não sei ao certo como se deu. Sou antropólogo e historiador, mas o mais importante está em minha pesquisa que, na maior parte do tempo, porém nem sempre, é sobre temas Indonésios. Foi um tanto quanto uma coincidência que comecei a estudar a Indonésia, mas isso teve um grande impacto na minha vida. Fiz um pouco de pesquisa no Brasil, nos Países Baixos, Austrália, Malásia e Singapura. Contudo, a grande parte é sobre a Indonésia, e sempre tento combinar insights antropológicos e históricos.

E quais autores fazem parte dessa história? Digo, com quais teóricos você dialoga em seus trabalhos? Quais autores inspiraram sua jornada?

Sim, bem... os autores - dos quais eu engajo em discussões - compõem uma longa lista, mas o mais importante para mim, e que me levou à Indonésia, foi um livro do Clifford Geertz chamado Agricultural Involution ${ }^{7}$. Li quando era um estudante de graduação, e trata sobre dois tipos diferentes de cultivo do arroz na Indonésia: Wet Rice e Dry Rice, onde nos arrozais correspondem a campos irrigados ou de cultivo itinerante ${ }^{8}$. Esses sistemas me deixaram tão intrigado que acabei por fazer pesquisas sobre o cultivo de arroz depois de formado. Então, sim, Geertz teve um grande impacto no meu trabalho. Outra pessoa que desempenhou efeito similar foi um dos meus orientadores de pósdoutorado: Dr. Peter Nas. Ele é um antropólogo urbano e sociólogo, que enfatizou em

\footnotetext{
${ }^{7}$ GEERTZ, Clifford. Agricultural Involution: the processo of agricultural change in Indonesia. Berkeley: University of California Press, 1963.

${ }^{8}$ Técnica de produção agrícola que consiste na derrubada de trechos de floriestas para posterior queima, o que no Brasil é chamado de queimadas (PEDROSO JÚNIOR; MURRIETA; ADAMS, 2008).
} 
seus trabalhos a importância da Sociologia do Conflito. Portanto, sempre que observarmos o que está acontecendo nas cidades, devemos olhar para quais grupos de interesses estão envolvidos no "fazer" dessa cidade. Um terceiro autor, que teve imprescindível impacto, sem dúvida, é Henri Lefebvre, que fora um dos primeiros a escrever sobre a produção social do espaço urbano - e que em termos gerais abrange grande parte do que eu pesquiso.

E sobre a Antropologia Holandesa, como você avalia a Antropologia em atividade aqui nos Países Baixos?

A Antropologia Holandesa é muito ampla, claro, então não sei muito bem por onde começar. Uma característica típica da nossa antropologia é a de ser muito empírica e, diante disso, a etnografia desempenha um papel importante. Quase não há antropólogos que trabalham somente no nível teórico. Mesmo pesquisadores seniores sentem vontade de continuar praticando pesquisa de campo, percebe-se a importância disso na antropologia holandesa. As temáticas também são abrangentes, portanto, podem ser sobre diversos tópicos, mas é antropologia cultural e social, então não temos os four fields da Antropologia Estadunidense ${ }^{9}$. O que acarreta pouco trabalho feito sobre préhistória ou linguística, esta realizada em outras disciplinas. Arqueologia nos Países Baixos é uma área realmente diferente. Curiosamente, quando falamos da história da disciplina, a antropologia holandesa voltava-se mais a trabalhos de campo noo sul global: África, Ásia e América Latina. Agora a antropologia "voltou para casa", então estamos trabalhando na Europa, incluindo os Países Baixos, tanto quanto em qualquer outra parte do mundo. Realmente não faz tanta diferença do "onde", enquanto pessoas de outras disciplinas podem perguntar, ou precisamos explicar o porquê de fazer pesquisas nos Países Baixos, no Brasil ou na Indonésia, percebe-se não haver muita diferença para nós entre os diferentes países, o mundo está globalizado e estamos todos conectados, temos que lidar uns com os outros.

\footnotetext{
${ }^{9}$ Correspondem às subáreas da Arquelogia, Antropologia Cultural, Antropologia Física e Linguística.
} 
Poderia nos dizer um pouco sobre autores holandeses? Quais vertentes são mais importantes aqui?

Bom, essa é uma pergunta complexa, porque não sei por onde começar. Alguns - como meu antigo orientador de pós-doutorado Peter Nas, e alguns estudantes dele como Rivke Jaffe - foram importantes antropólogos urbanos. Todos trabalham na tradição da Sociologia do Conflito. Por outro lado, um colega do meu antigo departamento, e que realmente me inspira, Mattijs van de Port, está fazendo pesquisa no Brasil em diferentes tópicos, mais no campo da religião e em como as pessoas criam o sentido do mundo de um jeito bem... cultural e não acho que chega a mencionar [perspectivas sobre] poder ou desigualdade, ele tem ciência sobre, mas não é o interesse dele. Está muito mais curioso em falar sobre como as pessoas criam ou tomam a percepção do mundo. O ponto que me intriga é que ele está escrevendo cada vez menos e está entrando cada vez mais na área audiovisual, percebo que isso é uma tendência na antropologia, vemos mais e mais pessoas interessadas em Antropologia Visual.

Por que a Indonésia? Sei que ela é muito importante no seu currículo, mas por que você escolheu Indonésia em especifico?

Por que Indonésia? Em alguns dos meus estudos, como estudante de graduação, tive que escolher uma disciplina optativa. Tínhamos que escolher entre quatro regiões, quatro países do mundo. Eu escolhi a Indonésia por nenhum outro motivo se não o de existir um romance holandês muito famoso escrito no período colonial chamado "Max

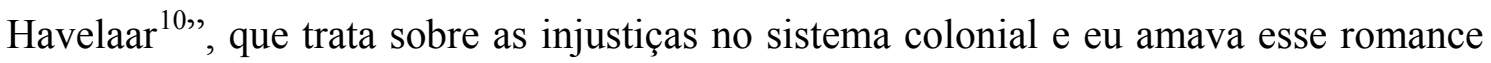
por isso escolhi a disciplina sobre Indonésia. Durante esse curso li o livro de Clifford Geertz que citei anteriormente,. Acabei por desenvolver um interesse mais antropológico pela Indonésia. Durante esse período tínhamos a chance de fazer pesquisa por um tempo no exterior, fui estudar a cultura do arroz na Indonésia. Depois estudei o idioma, já que precisamos aprender a falar a língua, e por aí em diante, gradualmente eu me tornei um especialista na Indonésia. Tudo ocorreu em passos pequenos. Depois, e somente depois, quando iniciei como estudante de pós-doutorado, percebi que por conta do passado colonial existe uma enorme quantidade de recursos em bibliotecas e arquivos nos Países Baixos sobre a Indonésia. Então, de todos os países, Indonésia para

\footnotetext{
${ }^{10}$ Multatuli (DEKKER, Eduard Dowes). Max Havelaar. Veneza/São Paulo: Âyiné, 2019.
} 
um antropólogo holandês que estuda sobre, tem grande vantagem pelas excelentes bibliotecas. Foi assim que passo a passo eu me envolvi com a Indonésia. No restante à parte, a origem se deu por amar um romance colonial. Não tenho nenhuma relação com os tempos coloniais. Não tenho família que trabalhou em colônias. É mais uma coincidência e um passo a passo em se tornar interessado pela Indonésia. Atualmente na verdade eu adoraria fazer pesquisa em outros países, nos Países Baixos, no Brasil, além de outros que gostaria de ir também. O problema é termos tão pouco tempo para pesquisa, e eu teria que investir muito tempo para ser capaz de trabalhar no mesmo nível que consigo realizar com a Indonésia. Então sim, se eu quiser realizar mais pesquisas no Brasil, teria que aprender português, conhecer livros importantes sobre o Brasil, criar uma rede de colegas pesquisadores com os quais pudesse cooperar, preciso aprender a lidar com as autoridades e não tenho tempo para fazer isso.

Na sua publicação sobre os catadores de lixo você faz uma comparação entre Belo Horizonte no Brasil e Jacarta, capital da Indonésia e fala sobre a mudança na atuação da lei, ou no processo de administração do lixo pela cooperativa. Poderia nos falar um pouco sobre essas pesquisas e sobre o trabalho de campo em ambos os países?

Sim, então, ainda que eu tenha feito alguma pesquisa em Florianópolis, essa pesquisa em Belo Horizonte foi realizada por uma mestranda, estudante nossa, e minha coautora Martina Morbidini. Portanto, o que é importante para nós é que o lixo esteja sendo reciclado o máximo possível para chegarmos o mais próximo de uma economia circular. O primeiro estágio desse processo de reciclagem são os catadores de lixo separando o lixo: trabalho que pode ser realizado por máquinas, mas nem sempre é melhor ou mais eficiente. Assim, os catadores são extremamente importantes. A questão também é que se você comparar os catadores de lixo no Brasil e na Indonésia, você verá que no Brasil e por toda a América Latina, eles são melhor organizados nas corporações, e que, a longo prazo, isso é bom pois oferece alguma proteção a eles - e ganham mais apreciação social do que os catadores de lixo na Indonésia. Então o papel social é muito mais reconhecido e eles ganham respeito por isso. Em compensação, você percebe que isso limita um pouco a liberdade, de modo que as cooperativas em uma via oferecem proteção aos catadores, mas reduzem sua autonomia e isso é uma visão geral - aliás é algo que peguei de Thomas Hylland Eriksen. Então ao falar de autores que tiveram 
grande impacto no meu trabalho, Eriksen certamente é um deles - que em oposição à ideia de segurança, essa que não abarca somente insegurança, mas também a liberdade. Se você procurar por segurança o tempo todo, o que não é ruim, você perde muita autonomia. Mas se você aceitar mais insegurança, você retém mais liberdade e com esse princípio geral, se você aplicar aos catadores de lixo na Indonésia, sem corporações, eles têm menos segurança, mas muito mais liberdade - assim conseguem fazer mais dinheiro.

\section{Mas quando o lixo começou a ser um questionamento para você?}

Eu comecei a me interessar pelo tópico do lixo por volta de dez anos atrás. Naquela época eu queria fazer trabalho de campo e estava trabalhando por algum tempo com recursos históricos, senti que era hora de voltar para o trabalho de campo antropológico. Eu queria realizar esse trabalho nas cidades, quis trabalhar com temas como desigualdade e pobreza, além de problemas ambientais. Então, combinando alguns dos meus interesses anteriores para pesquisa, comecei de baixo pra cima: na primeira parte do trabalho de campo só andava por duas cidades indonésias, tinha conversas com colegas das universidades indonésias questionando onde encontraria, nos arredores, se quisesse enxergar o meio ambiente, pobreza e as configurações urbanas. Somente depois tomei consciência da importância do lixo e dos catadores do lixo, então não surgiu como uma pergunta teórica, mas como uma curiosidade empírica.

Poderia nos dizer, na sua opinião, qual é o maior desafio na área que chamamos de Antropologia do Lixo/Resíduos a atualidade?

O maior desafio, no final das contas, é como reutilizar a produção do lixo. Nós criamos muito resíduo e lixo, muitas vezes sem necessidade. Se você olhar bem, e pegar uma perspectiva histórica, verá que nos Países Baixos você poderia ir numa padaria pedir por um pão e eles dariam um pão, mas agora se você for em um supermercado ele vai estar embrulhado em sacolas plásticas, por que disso? Não é necessário. Se você comprar coisas online, roupas, livros, o que for, agora mais já que as pessoas compram mais e mais online, os produtos estarão empacotados em caixas de papelão e estufados com plástico, isso tudo é resíduo desnecessário. O que é um grande problema na Indonésia, 
por exemplo, se você fosse comprar comida na rua - e existe todo um setor informal vendendo esse tipo de alimento - ele estaria embrulhado em uma folha de bananeira e ela é perfeita para a função: é orgânica, barata e abundante, excelente. Mas agora se for comprar estará embrulhada em plástico, que será embrulhado em outro plástico e assim sucessivamente. Ocorre principalmente se for comprar comida em shoppings. Incrível é comprar um petisco e ele às vezes estar embrulhado em seis, sete ou até oito tipos de embrulho. Tudo isso é lixo. Então a grande pergunta, eu acho, é: como reduzir o número de resíduo que nós estamos produzindo? Nas minhas pesquisas eu olho mais para, mas não somente, o lixo plástico, já que a Indonésia é um dos maiores contribuintes para a "plastic soup 11 " nos oceanos, e sigo todos os estágios do lixo pela cidade e vejo como nós podemos reciclar o máximo possível para evitar que seja levado aos oceanos.

Nós gostaríamos de saber como a antropologia se mostra fora da universidade aqui nos Países Baixos. Se, nas escolas, os alunos têm aulas de Antropologia ou Estudos Culturais no currículo - ou se isso é oferecido a crianças e adolescentes em outros lugares como, como por exemplo, nos museus?

Aqui nos Países Baixos nós não temos Antropologia nas escolas, às vezes encontramos algo parecido com Antropologia nas aulas de Geografia, em que há alguma sobreposição. Tem um pouco nas eletivas de Ciências Sociais, para que [os alunos] tenham algumas compreensões antropológicas. Mas, no geral, nas escolas não tem muita antropologia. Você vê alunos que iniciam o curso de Antropologia nas universidades sem saber o que esperar. O que acontece é que cada vez mais - já que nem todos os formados trabalham nas universidades, por ser impossível - os antropólogos desempenham [funções] no mercado de trabalho holandês, e eles acabam realizando todo tipo de cargo. Isso é o mais importante, [exercer essas] tarefas como antropólogos. Um exemplo é uma ex-aluna minha, que está trabalhando em incorporação de casas, construção de moradias, blocos de apartamentos. Então o corpo de funcionários consistia em engenheiros, advogados e especialistas financeiros, e ela foi a primeira cientista social ou antropóloga trabalhando para a empresa. O que ela precisou falar foi "bom, se você pensar em habitação, não é sobre quantos metros

\footnotetext{
${ }^{11}$ Termo utilizado para designar uma grande quantidade de plástico que polui os mares.
} 
quadrados você consegue construir, ou quanto vai custar, mas também, e principalmente, sobre as pessoas vivendo nos apartamentos para que isso reformule a concepção de alojamento. Você não deve pensar nos tijolos, mas pensar no usuário e como ele vai perceber esse espaço". Isso é óbvio, acho, para antropólogos, que se deve começar pelas pessoas e não pelas paredes. Mas para essa empresa foi uma grande sacada, e a carreira dela escalonou rapidamente, chegando aos grandes cargos dentro da corporação. E eu poderia dar vários outros exemplos. Então a antropologia é muito visível, vemos cada vez mais artigos em jornais escritos sob uma perspectiva antropológica. Ela está muito presente, mas não no currículo escolar. E sim, nós temos museus etnográficos, porém não é o lugar mais importante nas ciências sociais, em que você vê Antropologia.

Você poderia nos dar uma declaração sobre o projeto "Circular economy: anthroppologies of waste and innovative experiences between Netherlands and Brasil realizado entre a CAPES e NUFFIC", sobre os estudantes holandeses que fizeram trabalho de campo no Brasil e sobre os modelos teóricos ao pensar sobre o lixo?

Primeiramente, acho que o lixo é um tópico importante a ser estudado por antropólogos. Parte porque por si só é um problema de saúde pública deixar o lixo depositado onde está nas cidades ou em áreas rurais Então é necessário fazer algo com os resíduos. Na minha visão, agora com a intensificação da crise ambiental, é que nós devemos conservar [os materiais/resíduos] o máximo possível. Pensar o lixo não como descarte, mas como um recurso. Por isso é extremamente importante estudar lixo, e fazer isso em diferentes países para somar à discussão. O comparativo de diferentes perspectivas: comparar o Brasil aos Países Baixos e, possivelmente, outros países é relevante, portanto, bom que o faça em seus respectivos países; brasileiros estudando o Brasil e holandeses, os Países Baixos. Porém, você consegue introspecções extras se cruzar o oceano e realizar pesquisas fora, principalmente sobre seu próprio país - quando um brasileiro estuda os Países Baixos ele ganha noção sobre o Brasil e o oposto também é verdade, ou melhor, o contrário. Quando pesquisadores holandeses estudam o Brasil eles também aprendem sobre os Países Baixos. 
Poderia nos contar sobre sua parceria com a Professora Dr. ${ }^{a}$ Carmen Rial? Como iniciou?

Penso que com qualquer cooperação internacional, o que é importante, e digo de direito geral, ambos os lados devem contribuir com algo, mas é também fortemente baseado na confiança ou até mesmo na amizade. Acontece que Carmen Rial e eu nos conhecemos há muito tempo, não sei por quanto tempo... não se deve contar em anos, mas em décadas, isso é importante e influencia na vontade de investir em uma cooperação tão duradoura.

\section{REFERÊNCIAS}

CHUA, L.; FAIR, H. Anthropocene. In: F. Stein, S. Lazar, M. Candea, H. Diemberger, J. Robbins, A. Sanchez \& R. Stasch (Eds). The Cambridge Encyclopedia of Anthropology. Cambridge: Cambridge University, 2019.

COLOMBIJN, Freek; MORBIDINI, Martina. Pros and cons of the formation of wastepickers' cooperatives: a comparison between Brazil and Indonesia. Decision, 44 (2), 91$101,2017$.

GEERTZ, Clifford. Agricultural Involution: the processo of agricultural change in Indonesia. Berkeley: University of California Press, 1963.

PEDROSO JÚNIOR, Nelson Novaes; MURRIETA, Rui Sérgio Sereni, ADAMS, Cristina. A agricultura de corte e queima: um sistema em transformação. Boletim do Museu Paraense Emílio Goeldi. Ciências Humanas, vol. 3, nº 2. Belém, mai/ago, p.153 $-174,2008$.

RIAL, Carmen. O poder do lixo: abordagens antropológicas dos resíduos sólidos. Rio de Janeiro: Associação Brasileira de Antropologia, 2016. 
O lixo como uma problemática antropológica: Entrevista com Freek Colombijn

Recebido: $01 / 09 / 2020$

Aprovado: 08/12/2020 